\title{
Changing prospects for UK job market
}

\section{Richard Pearson}

\section{Britain's Chancellor Nigel Lawson, some say, is presiding over an economic 'boom'. But what likelihood is there that the recovery will result in employment opportunities?}

MARCH is the month of the UK budget when the Chancellor of the Exchequer reports on the financial state of the country and makes his major changes to taxes. This year there is a prospect of major tax cuts because of booming tax revenues as the economy continues its expansion for the fifth successive year. Although this is a long recovery period by historical standards, industrial output has only just returned to the level of 1979 while unemployment, at 2.7 million under the current counting system, is still exceptionally high. The figure becomes worse still when account is taken of the half million or more on special schemes and the fact that the new method of counting deflates the total relative to the figures given in the 1970 s. So how does the boom in the economy translate itself into jobs?

The early 1980 s saw a massive shakeout from manufacturing, with more than 2 million jobs lost in the decade to 1985 , an annual loss rate of 3 per cent. Much of that contraction was structural as businesses closed and uneconomic capacity was withdrawn. As a result, there was a significant growth in UK productivity as the activities with the lowest productivity have been removed. During the period to 1995 , this job loss is expected to continue, albeit at a slower rate, as companies seek further improvements in competitiveness by improving working methods, investing in new technology and continuing to cut out uneconomic capacity. So although

\begin{tabular}{lr}
\hline Employment change 1986-95 (thousands) \\
\hline Primary and utilities & -114 \\
Manufacturing & -467 \\
Construction & +169 \\
Distribution, transport & \\
$\quad$ and communications & +337 \\
Business and other services & $+1,369$ \\
Public services & +115 \\
Total & $+1,406$
\end{tabular}

output is expected to rise, productivity will go up more rapidly and jobs will continue to be lost. The long-term decline in employment in agriculture and the utilities is expected to continue, reflecting longer-term productivity gains.

Construction, by contrast, is likely to continue its recovery and create jobs, reversing the losses of the past decade. The main growth sectors will continue to be in retailing, hotels and catering, and particularly financial and business services, which will generate more than a million new jobs by 1995 , an annual growth rate of
3 per cent. In the public sector, modest growth is expected, driven by health and welfare needs. Self-employment will also keep on growing into the 1990 s benefiting, as will the growing number of small companies, from further subcontracting by the larger companies and the public sector. Across the whole economy, an extra 1.4 million jobs are expected.

Unfortunately for the unemployed, the working population will also continue to grow until 1990 before it starts to decline. The most dramatic component of change will be the massive decline in the number of workers aged under 24 , down by a quarter, which will be good for youth unemployment but which will also play havoc with recruiters seeking schoolleavers for jobs, training and places in further and higher education (see Nature 329, 470; 1987). Women's participation in the labour market will also continue to increase, partly because of more part-time job opportunities. The net effect will be a fall in unemployment of about 600,000 over the decade to 1995 , when the number of registered claimants will total about 2.5 million. Women will continue to be the beneficiaries of job growth, much of which will be in part-time jobs; their unemployment rate in 1995 will be about 6 per cent compared with 11 per cent for men. The figures for women will, however, continue to be depressed by the many women who would take work if available but do not register for benefits.

At an occupational level, job growth will continue to benefit managerial and professional workers while operative and labouring jobs will continue to disappear. About 0.9 million professional jobs will be generated, an annual increase of 1.75 per cent. It is estimated that by 1995 almost one in four of the labour force will be engaged in such jobs, and they will be the largest occupational grouping. The next largest will be sales and personal services, accounting for one in five, followed by managers, craft, clerical and operatives (see figure). The growth in the number of managers will be caused largely by structural changes whereby the growth in services generates a large number of small units, each headed by a manager, although the proportion of managers in business and related services will also rise. By contrast, the growth in professional occupations will result from their increasing their share of employment in all sectors, most notably in health, education and public administration where they will account for about half of all the jobs.

How then does this translate into messages for the job-seeker looking for new qualifications? The first point is that there is no universal linkage between occupations and qualifications. Second, the United Kingdom, like most other countries, has no systematic data on the skill content of jobs, let alone how the skills needed are changing. The evidence on qualifications shows many examples where there is no formal link with occupa-

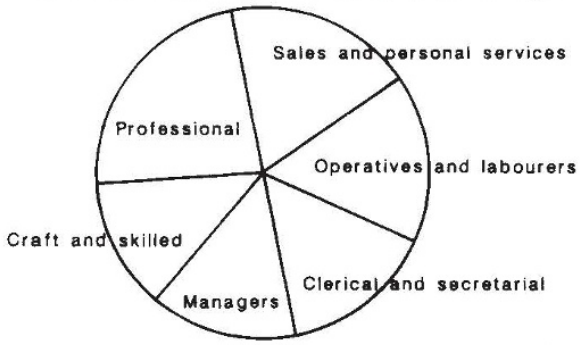

Occupational distribution predicted for 1995. Source for figure, Review of the Economy and Employment, Institute for Employment Research, 1987.

tions. For example, whereas nurses and doctors have to have relevant qualifications, only a minority of accountants have accountancy degrees. In information technology, electronics engineers need relevant degrees, usually in electronics or physics, but only a minority of programmers and systems analysts have computer science degrees. Moving on to the vexed question of what makes a manager, where masters' degrees in business administration are rare, there is not even a common language for the skills involved, job descriptions drawing on such indefinable attributes as leadership, analytical skills, problem-solving and communicative skills. There are many thousands of qualifications in the United Kingdom, some leading to specific careers, others of a more general nature. Very few relate to each other. A map is needed of existing qualifications and their comparability and value, after which an attempt could be made to link them to the changing occupational opportunities and skill needs of the economy. Until then, the job-seeker trying to adjust to the new opportunities will be floundering when it comes to choosing a relevant qualification.

Richard Pearson is at the Institute of Manpower Studies, Mantell Building, University of Sussex, Brighton BN1 9RF, UK. 